\title{
User cost estimation on flexible and rigid pavement
}

\author{
Fajar Sri Handayani, ${ }^{1, *}$, Rheza Imam Prabowo², Aria Ramandika Kurnia ${ }^{2}$, Florentina \\ Pungky Pramesti ${ }^{2}$, Mochamad Agung Wibowo ${ }^{3}$, and Ary Setyawan ${ }^{2}$ \\ ${ }^{1}$ Doctoral Program in Civil Engineering, Faculty of Engineering, Sebelas Maret University, Surakarta, \\ Indonesia \\ ${ }^{2}$ Civil Engineering Departement, Sebelas Maret University, Surakarta, Indonesia \\ ${ }^{2}$ Civil Engineering Departement, Diponegoro University, Semarang, Indonesia
}

\begin{abstract}
The unsatisfactory condition of Indonesia's local roads needs to be improved to support the national transportation network. However, construction activities to improve it often have negative impacts, among other: an increase of user cost. This article aims to calculate user cost generated by flexible and rigid pavement construction. This study was carried out on a local road in Indonesia. Life cycle cost analysis (LCCA) method is used to analyse the user cost. The results show that user cost of flexible pavement construction of 10 years and 20 years' design life are US\$ 734,290 and US\$449,830 respectively, futhermore user cost of rigid pavement construction of 10 years and 20 years' design life are US\$ $1,994,920$ and US\$ 1.203 .640 respectively. These indicate that the longer the analysis period, the more economical the user cost.
\end{abstract}

\section{Introduction}

The unsatisfactory condition of Indonesia's local roads needs to be improved to support the national transportation network. Based on data from the Ministry of Public Works and Public Housing, the length of local roads in 2015 is $423.578 \mathrm{~km}$ with an average reliable road condition of $59 \%$. Therefore, the government's efforts to improve local road satisfaction becomes very important. However, construction activities to improve it often have negative impacts, among other: an increase of user cost. User costs originate primarily from vehicle operating costs (i.e., vehicle wear and tear, fuel consumption, repairs and maintenance), delay costs (e.g., from an increase in time required to travel between two points as a result of work zone or congestion), and crash coasts (which are often a result of driver error and other factors not related to the roadway conditions and, as a result, are generally not factored in to life cycle cost analysis, LCCA) [1]. User delay costs are generally computed in consideration of vehicle class, trip type and trip purpose. This study focuses on calculating user cost estimation on flexible and rigid pavements. The study of

\footnotetext{
* Corresponding author: fajr_hani@yahoo.co.id
} 
user cost estimation on flexible and rigid pavements is important because user cost analysis is part of the total investment cost analysis and the results of this study are taken into account in planning and decision making. Details concerning the computation of user costs can be found in the National Cooperation Highway Research Program [2]. Free software for computing these costs is part of the FHWA RealCost LCCA program [3]. Babashamsi, et al used LCCA to evaluate the efficiency of alternative costs based on net present value concept. Cost evaluation to obtain an optimal pavement life cycle cost is important thing to do [4]. The cost of life cycle should include the variables that control future costs [5]. Lifecycle cost analysis is a process for evaluating the total economic worth of a usable project segment by analysing initial costs and discounted future costs, such as maintenance, user costs, reconstruction, and rehabilitation over the life of the project segment [6]. Ram et al. studied a series of Michigan concrete pavement projects using LCCA, concluding that higher levels of sustainability are achieved with increased pavement longevity [7]. Embacher and Snyder used LCCA to investigate actual maintenance and rehabilitation costs and strategies for concrete and asphalt pavements in two Minnesota counties, documenting the impact of differing maintenance strategies on the normalized cost (adjusted for varying traffic levels) of comparable pavements [8].

\subsection{RealCost LCCA software}

The most widely accepted and adopted LCCA tool for pavement applications currently used in U.S. is the FHWA's RealCost Software. RealCost is essentially an MS-Excel ${ }^{\circledR}$ spreadsheet-based automated version of the LCCA methodology contained in the FHWA's LCCA Technical Bulletin [9]. The program can be used to compute life-cycle costs for agency and work zone user costs associated with new construction, maintenance, and rehabilitation activities using both deterministic and probabilistic approaches. The component of the user cost are vehicle operating costs and delay cost. Vehicle operating cost is the cost associated with maintaining a vehicle function during the operation time. Delay cost is the cost that occurs due to lane closures or vehicle speed within the work zone areas associated with construction activities. The cost of work zone delay is calculated using formula (1) - (3) [10].

$$
\begin{gathered}
\text { Stop Delay = Average Length of Queue / Queue Speed } \\
\text { Work Zone Delay }(\text { WZD) = Stop Delay + Speed Reduction Delay }
\end{gathered}
$$

Cost of Work Zone Delay = WZD x Vehicle Affected x Work Zone Duration x VOT (3)

\subsection{Research design}

This study aims to evaluate the user costs that must be incurred for flexible and rigid pavement construction. Primary and secondary data in this study include project details, unit price of work, volume of existing and planning road segment, analysis option, discount rate, traffic data, traffic hourly distribution, vehicle operating cost, value of user time, added time and vehicle stopping cost, work zone length, work zone duration, work zone speed limit, and lanes open in each direction during work zone. The design of flexible and rigid pavement thickness is based on component analysis method and manual pavement design 2012, respectively. Two alternatives of design life are simulated for each type of pavement, namely a design life of 10 and 20 years. This study was conducted based on cases local road construction. User costs of those alternatives are analysed using Life cycle cost analysis program-RealCost 2.5 . 


\section{Result and discussion}

\subsection{Flexible pavement}

The result of the calculation of the thickness of the flexible pavement layer obtained using the Component Analysis method is $14.86 \mathrm{~cm}$ for the 10 year-design life and $18.86 \mathrm{~cm}$ for the 20 year-design life. The calculation of budget plan of flexible pavement cost with the 10 and 20 year-design life is $\$ 873,036,000$ and $\$ 1061,682,000$ respectively. The result of LCCA analysis with RealCost 2.5 program can be seen in figure 1 and 2.

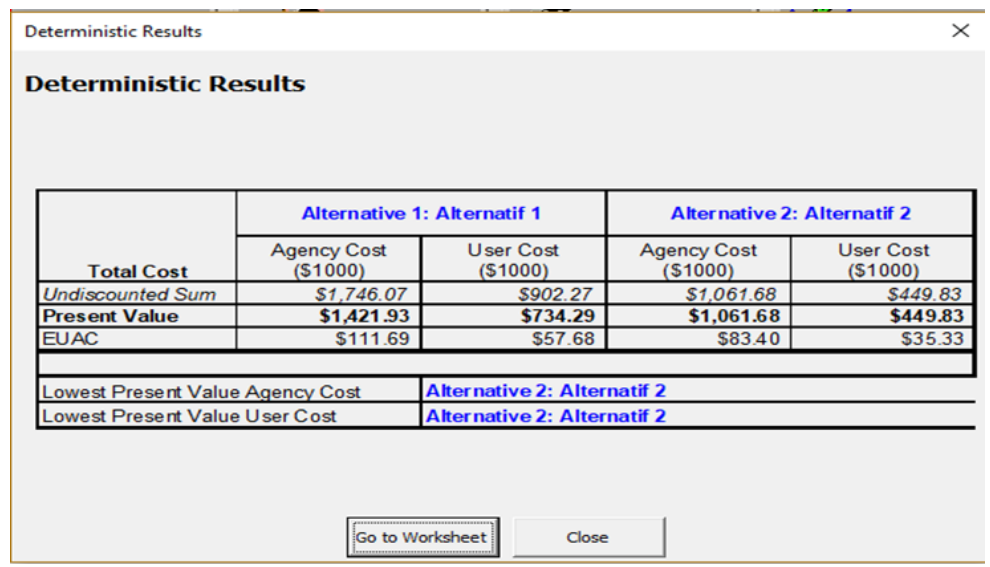

Fig. 1. Deterministic results.

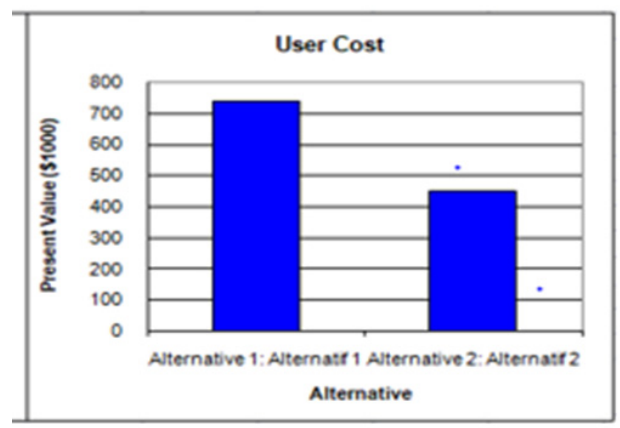

Fig. 2. User cost deterministic result.

The recapitulation of LCCA analysis results is as follows:

Table 1. The result of the calculation of the thickness and LCCA of the flexible pavement.

\begin{tabular}{|c|c|c|}
\hline & $\begin{array}{c}\text { Alternative 1 } \\
\text { 10 years' design life }\end{array}$ & $\begin{array}{c}\text { Alternative 2 } \\
\text { 20 years' design life }\end{array}$ \\
\hline Thickness of pavement & $14,86 \mathrm{~cm}$ & $18,86 \mathrm{~cm}$ \\
\hline Budget plan & $\$ 873,036,000$ & $\$ 1,061,682,000$ \\
\hline User cost & $\$ 734,290$ & $\$ 449,830$ \\
\hline
\end{tabular}

Based on Table 1 above, alternative 1 has a smaller cost budget than alternative 2 because the pavement thickness is planned to be thinner. While the deterministic result of the RealCost 2.5 program shows that alternative 1 requires a higher user cost than alternative 2 . 
This is because for the design alternative with shorter design life, if the design life has been exceeded, the user cost of reconstruction will be calculated and then added to the total user cost, over an analysis period. The analysis period in this case means that this study compared the twenty-year life of design alternative 2 against a user cost of design alternative 1 plus user cost of reconstruction with design alternative 1 in ten years.

\subsection{Rigid pavement}

The design of rigid pavement design has been done with Pavilion Design Method as of 2012 with the result of thickness of pavement on Alternative I (10 years' design life) of 18 $\mathrm{cm}$ and Alternative II (20 years' design life) of $20 \mathrm{~cm}$.

The calculation of the budget plan of flexible pavement cost with the 10 years' and 20 years' design life are $\$ 306,983$ and $\$ 320,254$ respectively.

After the analysis is done with the program, the output of the program is then a deterministic result. Deterministic Results (Agency Cost \& User Cost) are shown in Figures 3 and 4 .

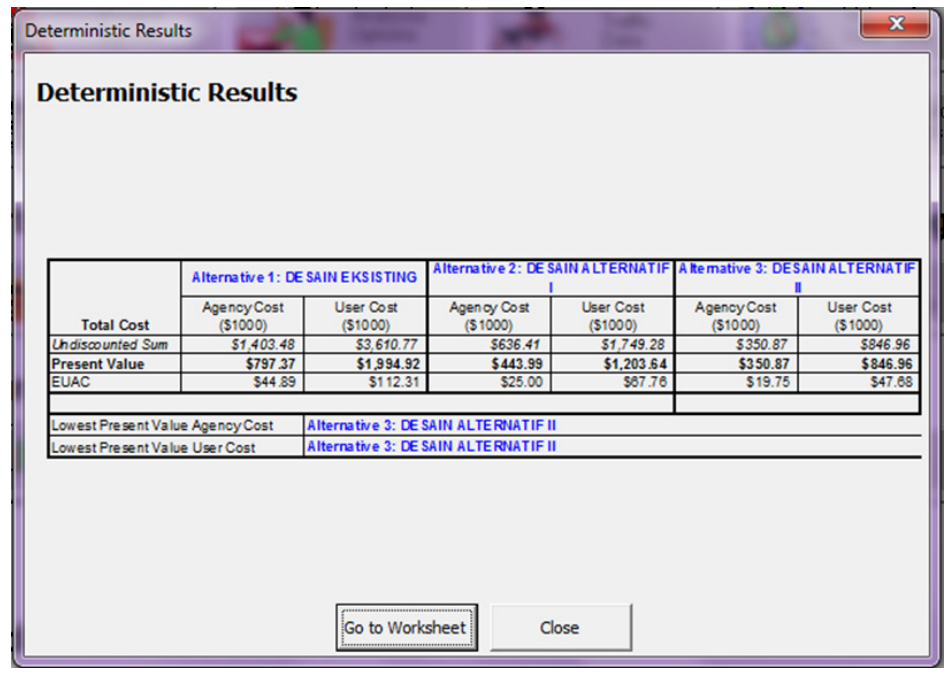

Fig.3. Deterministic results.

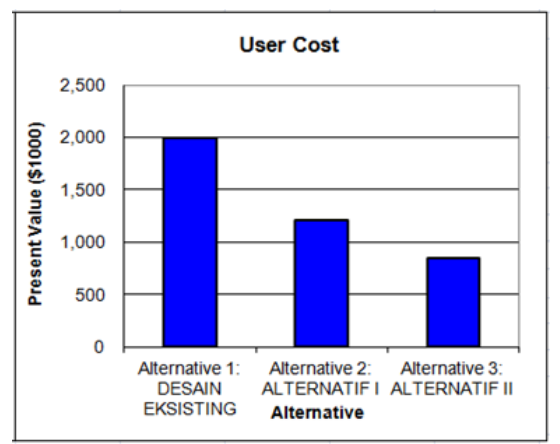

Fig. 4. User cost chart.

The recapitulation of LCCA analysis results is as follows: 
Table 2. The result of the calculation of the thickness, budget plan, and LCCA of the rigid pavement.

\begin{tabular}{|c|c|c|}
\hline & $\begin{array}{c}\text { Alternative 1 } \\
\text { 10 years' design life }\end{array}$ & $\begin{array}{c}\text { Alternative 2 } \\
\text { 20 years' design life }\end{array}$ \\
\hline Thickness of pavement & $18 \mathrm{~cm}$ & $20 \mathrm{~cm}$ \\
\hline Budget plan & $\$ 306,983$ & $\$ 320,254$ \\
\hline User cost & $\$ 1,994,920$ & $\$ 1,203,640$ \\
\hline
\end{tabular}

Based on Table 2 shown above, Alternative 1 has a smaller cost budget than the second alternative because the pavement thickness is planned to be thinner. While the deterministic result of the RealCost 2.5 program shows that alternative 1 requires a higher user cost than alternative 2 . This is because for the design alternative with shorter design life, if the design life has been exceeded, the user cost of reconstruction will be calculated and then added to total user cost, over an analysis period. The analysis period in this case means that this study compared the twenty-year life of design alternative 2 against a user cost of design alternative 1 plus user cost of reconstruction with design alternative 1 in ten years.

\section{Conclusion}

The results show that user cost of flexible pavement construction of 10 years and 20 years' design life are US\$734,290 and US\$449,830 respectively, furthermore user cost of rigid pavement construction of 10 years and 20 years' design life are US\$1,994,920 and US\$1.203.640 respectively. Calculations using the LCCA method show that planning with a longer design life yields more economical value. Because for the design alternative with shorter design life, if the design life has been exceeded, the user cost of reconstruction will be calculated and then added to total user cost, over an analysis period.

\section{References}

1. T. J. Van Dam., J. T. Harvey., S. T. Muench., K. D. Smith., M.B. Snyder., I. L. Al- Qadi., H. Ozer., J. Meijer., P. V. Ram., J. R. Roesler., and A. Kendall. Toward sustainable pavement systems: a reference document, Federal Highway Administration, Washington DC (2015)

2. National Cooperation Highway Research, Guide for mechanistic-empirical design of new and rehabilitated pavement structures. Transportation Research Board, Washington DC (2004)

3. Federal Highway Administration, Life-cycle cost analysis: RealCost user manual. RealCost version 2.5. Federal Highway Administration, Washington DC (2010)

4. P. Babashamsi., N. Yusoff., H. Ceylan., N. G. M. Nor., and H. S. Jenatabadi., International Journal of Pavement Research and Technology, 9(4), 241-254 (2016)

5. I. Mirzadeh., A. A. Toller., and B. Birgisson., Structure and Infrastructure Engineering J. 10(12), 1638-1647 (2014)

6. Federal Highway Administration, Improving transportation investment decisions through life cycle cost analysis. Federal Highway Administration, Washington DC (2013) 
7. P. Ram., T. J. Van Dam., J. Meijer., and K. D. Smith., Sustainable recycled material for concrete pavement. Michigan Department of transportation, Lansing, MI (2011)

8. R. Embacher, and M. B. Snyder, Transportation research record 1749, Transportation research Board, Washington DC (2001)

9. J. Wall., and M. R. Smith., Life cycle cost analysis in pavement design. Interim Technical Bulletin. Federal Highway Administration, Washington DC (1998)

10. M. Batouli., M. Bienvenu., A. Mostafavi., Transportation Research Part D 52 (2017) 